\title{
Delayed Visual Maturation - A Clinical Case
}

\author{
BY MARIE-EVE CORBEIL, OD, MSC
}

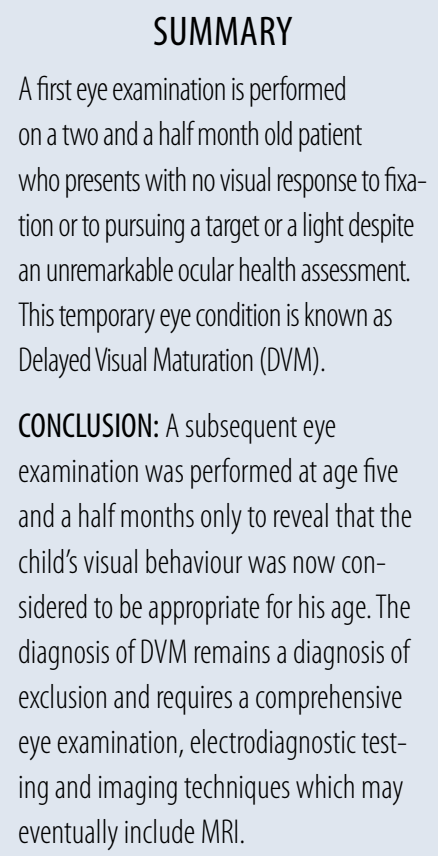

SUMMARY

A first eye examination is performed on a two and a half month old patient who presents with no visual response to fixation or to pursuing a target or a light despite an unremarkable ocular health assessment. This temporary eye condition is known as Delayed Visual Maturation (DVM).

CONCLUSION: A subsequent eye examination was performed at age five and a half months only to reveal that the child's visual behaviour was now considered to be appropriate for his age. The diagnosis of DVM remains a diagnosis of exclusion and requires a comprehensive eye examination, electrodiagnostic testing and imaging techniques which may eventually include MRI.

\section{Introduction}

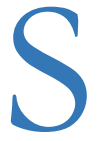
uspected abnormal vision in a newborn should not be taken too seriously. In fact, in $80 \%$ of cases, the professional discovers, upon examination, an obvious cause of visual impairment such as a cataract, glaucoma or albinism. ${ }^{1}$ Sometimes, as with Leber congenital amaurosis, it is instead marks on the retina, pupil anomalies or nystagmus. Other anomalies, such as cortical blindness, are accompanied by major neurological disorders. However, if it is simply delayed visual maturation, all the objective tests may be normal, which complicates the diagnosis. Electrodiagnostic testing then becomes very helpful for making a differential diagnosis between the various conditions and guiding the parents regarding the permanent or temporary aspect of the reduced vision.

\section{Case report}

A.J., a boy at two-and-a-half months of age, is brought in by his mother for a comprehensive eye examination. She noticed that A.J. seems to have a vision problem because he does not react to visual stimuli. He smiles when he hears human voices, but does not react to faces. A.J.'s history is otherwise unremarkable: term pregnancy with no complications, good health, no family history of systemic or eye problems. Upon examination, visual acuity via preferential looking, the ability to look at and track a light or large object, the presence or absence of nystagmus, pupillary reflexes, external examination, the ocular fundus by direct and indirect ophthalmoscopy and retinoscopy under cycloplegia are assessed (table 1). No particular anomalies were detected.

Given the young age of the patient and the absence of any visible ocular pathology, a follow-up in one-and-a-half months was then recommended. At that follow-up, the same results were obtained upon examination.

What is the most likely diagnosis?

\section{Discussion}

An infant with delayed visual maturation (DVM) does not fix or follow a target or light, despite an eye exam that may be completely normal. In most cases, the infant does not blink at the approach of a bright light or object. Normally, the fixation reflex may be seen in the infant at 32 weeks gestation. ${ }^{2,3}$ At that age, preferential looking is also present. ${ }^{4}$ In fact, newborns will prefer to look at a pattern or moving target rather than a uniform surface. Horizontal

\section{TABLE 1: Tests and Results of A.J.'s Eye Exam}

\begin{tabular}{|l|l|}
\hline Tests & Results \\
\hline Visual acuity (Teller card) & Nil \\
\hline Fixation & Absent \\
\hline Motility & Nil \\
\hline Nystagmus & Absent \\
\hline Pupillary reflexes & Normal \\
\hline External exam & Normal \\
\hline Ocular fundus & NO, normal retina and macula \\
\hline Refraction (retinoscopy under cycloplegia) & OD $+1.25 /-0.50 \times 180$ \\
& OS +1.50 \\
\hline
\end{tabular}


TABLE 2: Types DVM ${ }^{9}$

\begin{tabular}{|l|l|}
\hline Types & Characteristics \\
\hline 1 & Isolated DVM \\
\hline 2 & DVM and mental retardation or epilepsy \\
\hline 3 & DVM and primary visual anomalies \\
\hline
\end{tabular}

TABLE 3: Types of DVM ${ }^{10}$

\begin{tabular}{|l|l|l|l|}
\hline Types & Characteristics \\
\hline 1 & DVM is the primary anomaly & $1 \mathrm{a}$ & Normal perinatal period \\
\cline { 2 - 4 } & & $1 \mathrm{~b}$ & Abnormal perinatal period \\
\hline 2 & DVM and lasting neurological development disorder \\
\hline 3 & DVM, nystagmus and albinism \\
\hline 4 & DVM and bilateral congenital eye disorders \\
\hline
\end{tabular}

tracking is present at birth, but vertical tracking develops between four and six weeks of age. Patients with DVM are typically between two and four months old and are in good health. They generally start to fix and follow objects at around six months of age. DVM is not a new condition. As early as 1926, Beauvieux was describing infants who showed little or no reaction to visual stimuli at birth. ${ }^{5}$ Since then, a number of authors have described similar cases using different terms: myelogenosis retardata, disscociated visual development or delayed visual development. ${ }^{6,7}$ Illingworth (1961) was the first to introduce the term delayed visual maturation. He described the condition of two infants, with no developmental delay, whose normal reaction to visual stimuli did not appear until six months of age. ${ }^{8}$ En 1981, Uemera et al. introduced a DVM classification having three categories (table 2). ${ }^{9}$ Fielder et al. altered that classification by instead suggesting four types with subcategories (table 3). ${ }^{10}$
DVM is an exclusion diagnosis requiring a comprehensive eye exam, electrodiagnostic testing and potentially magnetic resonance imaging (MRI). The use of visual evoked potentials (VEP) is common. However, the results vary considerably from one study to the next. Some studies have reported that infants with DVM also show an initial VEP deficit. Flash VEPs may be absent ${ }^{7}$, show latency ${ }^{11}$ or an abnormal shape ${ }^{10}$ in the first months of life with gradual improvement after that. Pattern VEPs show similarities, but vary greatly depending on the stimulus used. The electroretinogram (ERG) is abnormal only if the DVM is associated with retinal anomalies. ${ }^{12}$ The main differential diagnoses are shown in table 4. All these conditions have a comparable initial clinical presentation. The two conditions that are the hardest to rule out are bilateral pupillary hypoplasia and cortical blindness. In the first instance, the symmetrical aspect of the optic nerves can result in the pathology going undetected; the diagnosis of the second condition, which is not always easy to rule out at a young age, often requires an MRI.

The prognosis of infants with delayed visual maturation varies considerably from one study to the next and greatly depends on the type of pathology. Several authors report isolated cases of $\mathrm{DVM}^{7,11,13}$ while others find them associated with other neurological disorders. ${ }^{1}$ The isolated cases end up correcting themselves on average around the $14^{\text {th }}$ week according to Fielder ${ }^{10}$ and between three and eight months according to most of the authors. ${ }^{12,14,15}$ That recovery is fast. In a few days, the infant wakes, is interested in and smiles at its surroundings. The comprehensive eye exam is then comparable to that of other normal infants of the same age. When DVM is associated with mental retardation (type 2 according to Fielder), the prognosis is not as good because of the associated neurological anomalies. When DVM is associated with another ocular defect such as albinism, aniridia or something else (type 3 and 4 according to Fielder), initial vision seems totally absent or less than what the detected ocular defect suggests. However, in a few months, on average five months, some vision appears, corresponding with what would be expected with the associated anomaly. ${ }^{10}$

A number of hypotheses were put forth in the past for determining the cause of DVM. According to Beauvieux, it was caused by myelination delay. ${ }^{5}$ It was long considered that the rear visual pathways were completely myelinated in the first months of life. ${ }^{16}$ More recent studies show that the fibres of the optic nerve start myelination at birth, but 
TABLE 4: Main Differential Diagnoses

\begin{tabular}{|l|l|}
\hline Conditions & Characteristics \\
\hline Leber congenital amaurosis & Frequent nystagmus \\
& Pupillary anomaly \\
& Retinal variation \\
& Major ERG alteration \\
& Total or severe VEP deficit \\
\hline Albinism & Possible nystagmus \\
& Ocular fundus hypopigmentation \\
& Normal ERG and VEP \\
& Iris transillumination enables \\
& diagnosis \\
\hline Cone dystrophy & Major ERG alteration \\
& VEP affected \\
& Early nystagmus and photophobia \\
\hline Bilateral pupillary hypoplasia & Normal ERG \\
& VEP $+/$ - affected \\
& CAT scan enables diagnosis \\
\hline Cortical blindness & Normal ERG \\
& Major VEP deficit \\
& MRI enables diagnosis \\
& \\
\hline
\end{tabular}

that the process may continue until two years of age. ${ }^{17}$

According to Hoyt, however, DVM was caused by a delay in the maturation of certain cortical functions $^{18}$, whereas Tresidder believes it is an abnormality in the extrageniculate system predominating in the first two months of life, while the purely cortical functions emerge after that time. ${ }^{19}$

\section{Conclusion}

At five-and-a-half months of age, A.J. was examined again. He presented with visual behaviour within the normal limits for an infant of his age. The mother noticed that he reacts normally to visual stimuli.
3. Wolff PH, Ferber R. The development of behavior in human infants, premature and newborn. Annu Rev neurosci 1979;2:291-307.

4. Dubowitz L. A study of visual function in the premature baby. Child Care Health Dev 1979;5(6):399-404.

5. Beauvieux J. La pseudo-atrophie optique des nouveaux-nés (disgénésie myélinique des voies optiques). Ann d'oculiste 1926;163:876-921.

6. Keiner GBJ. New viewpoints on the origin of squint. Br J Ophthalmol 1952;36(6)334.

7. Mellor DH, Fielder AR. Dissociated visual developmet, electrodiagnostic tests in infants who are "slow to see". Dev. Med child Neurol 1980;22(3):327-335.

8. Illingworth RS. Delayed visual maturation. Arch Dis Child 1961;36:407-409.

9. Umera Y, Agucci Y, Katsumi, O. Visual development delayed. Ophthalmic paediatrics Genetics 1981;1:4-11

10. Fielder AR et al. Delayed visual maturation. Trans Ophthalmol Soc UK 1985;104(6):653661.

11. Harel S, Holtzman M, Feinsod M. Delayed visual maturation. Arch Dis Child 1983;58(4):298-299.

12. Mercuri E, et al. The aetiology of delayed visual maturation: short review and personal findings in relation to magnetic resonnance imaging. Euro Paediatric Neurol 1997;1(1):31-34.

13. Dudgeon J. Electrodiagnostic tests in visual assessment in children. Dispensing Optician 1977;29:222-229.

14. Lambert SR, Kriss A, Taylor D. Delayed visual maturation. A longitudinal clinical and electrophysiological assessment. Ophthalmology. 1989;96(4):524-529.

15. Harris CM et al. Delayed visual maturation in infants : A disorder of figure-ground separation? Brain Reserch Bulletin 1996;40(56):365-369.

16. Carvioto H. Electron microscopic studies of the developing human nervous system. II. The Optics nerve. J Neuropathol Exp Neurol 1965;24:166-167.

17. Maggon EH, Robb RN. Development of myelin in the human optic nerve and track. Arch Ophthalmol 1981;99:665-669.

\section{References}

1. Cole GF, Hungerford J, Jones RB. Delayed visual maturation. Archives of Disease in Childhood 1984;59(2):107-110.

2. Vehrs S, Baum D. A test of visual responses in the newborn. Dev Med Child Neurol 1970;12(6):772-774.
18. Hoyt CS. Constenbader lecture. Delayed visual maturation: the apparently blind infant. Journal of American Association for Pediatric Ophthalmology and Strabismus 2004;8 $\operatorname{Vol}(3): 215-219$

19. Tresidder J, Fielder AR, Nicholson J. Delayed visual maturation: ophthalmic and neurodevelopmental aspects. Developmental medicine and child neurology. 1990;32(10): 372-381. 